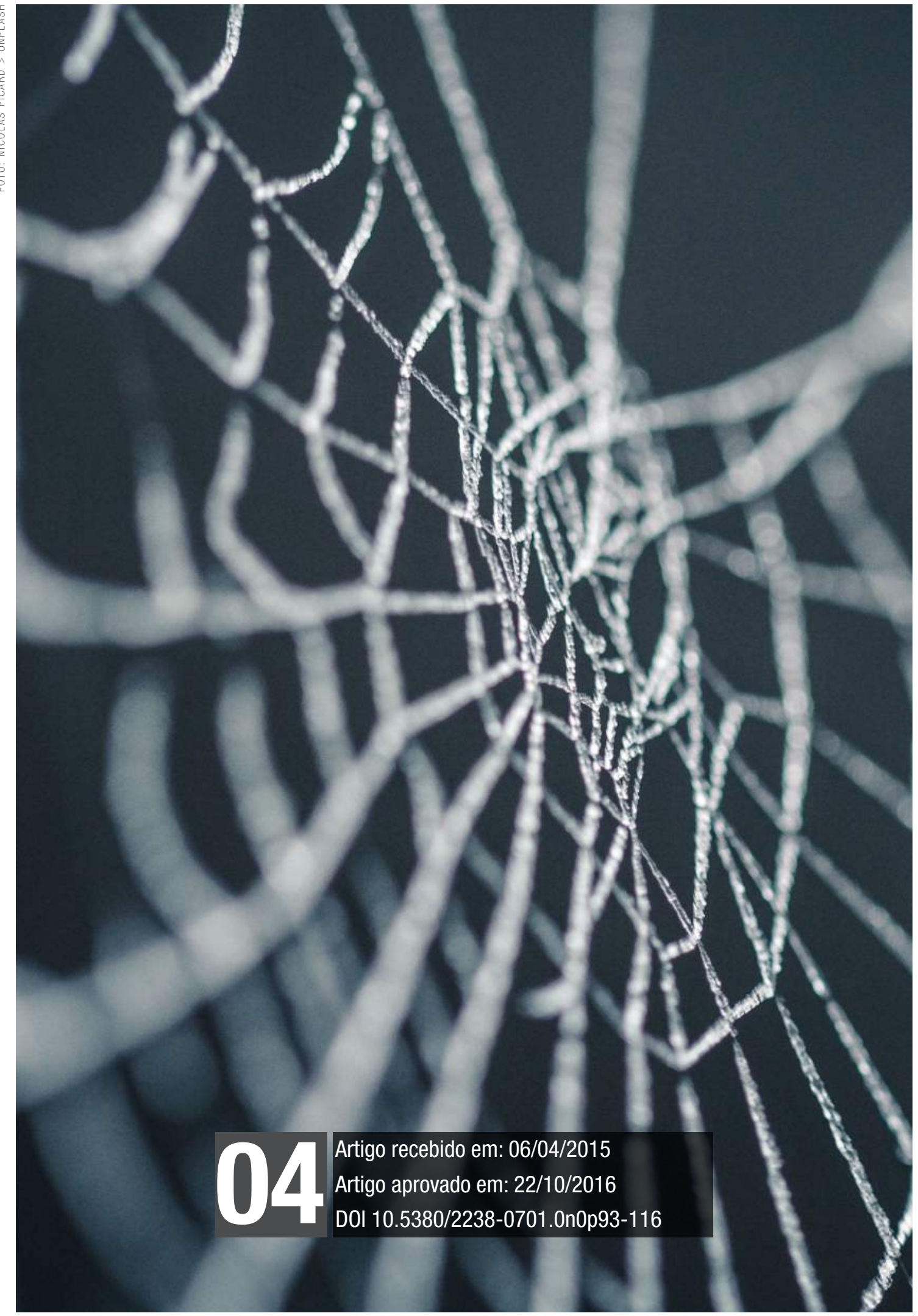


Cobertura Midiática. Manifestos. Repercussão. 


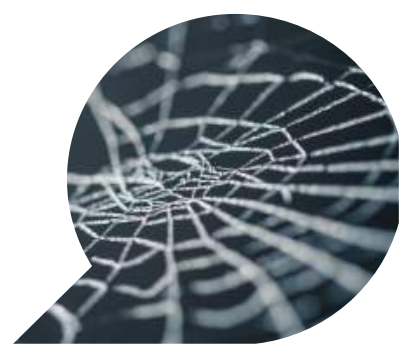

\section{O Twitter como mecanismo de voz: um estudo do uso hashtag na cobertura midiática do Jornal Nacional durante os manifestos de junho de 2013 no Brasil}

Twitter as a social voice: a study of the hashtag on media coverage of Brazil's protests in June 2013 from the perspective of Jornal Nacional

El Twitter como um médio de voz: um estudio de la hashtage la cobertura mediática del Jornal Nacional durante las manifestaciones de junio de 2013 en Brasil

\begin{tabular}{l} 
RODRIGO RODEMBUSCH ${ }^{1}$ \\
\hline GABRIELA SCHUCH KASTNER \\
\hline Resumo: Em meio a um ambiente em que a rede social deixa de \\
ser apenas mais uma ferramenta de compartilha mento e se tor- \\
na um mecanismo potente entre os cidadãos, o presente artigo se \\
propõe a analisar o uso da hashtag como forma de agrupamento \\
da opinião massiva. Para isso, serão utilizados conceitos de cultura \\
participativa de Shirky, bem como a indignação em rede abordada \\
na obra de Castells. Pierre Levy e conceitos de inteligência coletiva
\end{tabular}

\footnotetext{
${ }^{1}$ Doutorado em Ciências da Comunicação (Unisinos) e mestre pela Deutsche Welle (Alemanha) em International Media Studies, é formado em Comunicação Social/Jornalismo pela Universidade Federal do Rio Grande do Sul (1999) E-mail: r.rodembusch@gmail.com

2 Mestrado em Ciências da Comunicação (Unisinos). Bacharel em Comunicação Social - Jornalismo (2011) e Especialista em Televisão e Convergência Digital (2014) pela mesma instituição. E-mail: schuch.gabriela@gmail.com
} 
justificaram a motivação da massa em se mobilizar. Como objeto de estudo, apresento uma análise feita com base na mensuração dos tuites disparados entre 13 e 18 de junho, entre $20 \mathrm{~h}$ e $21 \mathrm{~h}$, com a hashtag \#JornalNacional.

Palavras-chave: Cobertura midiática; Manifestos; Repercussão; Análise de conteúdo; Twitter.

Abstract: In an environment where social networking is no longer just a sharing tool and it becomes a powerful mechanism between citizens, this article aims to analyze the use of the hashtag as a form of media criticism. Therefore, it will be used the concepts of participatory culture from Shirky and the concept of indignation addressed by Castells. Pierre Levy and the concept of collective intelligence justified the mass motivation to mobilize. As object of study, we present an analysis based on the measurement of tweets posted between June 13th and 18th, between 8pm and 9pm, with the hashtag \#JornalNacional.

Keywords: Media coverage; Protests; Repercussion; Content analisys; Twitter.

Resumen: En un ambiente donde la rede social ya no es sólo una herramienta de intercambio y se convierte en un poderoso mecanismo para los ciudadanos, este artículo tiene como objetivo analizar el uso del hashtag como una forma de crítica de los medios de comunicación. Por tanto, se utilizarán los conceptos de cultura participativa de Shirky e la indignación de Castells. Pierre Levy y los conceptos de inteligencia colectiva justificaron la motivación de masas a movilizarse. Como objeto de estudio, presentamos un análisis basado en la medición de los tweets lanzados entre el 13 y 18 de junio, entre las $20 \mathrm{~h}$ y las $21 \mathrm{~h}$, con el hashtag \#JornalNacional.

Palabras clave: Cobertura periodística; Protestas; Repercusión; Análisis de contenido; Twitter. 


\section{Introdução}

Vivemos um cenário atual em que muito do que é feito só é validado pela existência nas redes sociais. Esse é um fenômeno em evolução que teve início na criação da internet, passando pela horizontalidade da informação - conceito de Castells, primordial no presente estudo - até chegar a um contexto de web em que tudo é urgente e deve ser publicado full time - descrito por Wolton.

Thompson propõe uma análise sociológica da mídia por meio das formas de interação que ela cria entre os indivíduos. Para o autor, "o uso dos meios de comunicação implica a criação de novas formas de ação e de interação no mundo social, novos tipos de relações sociais e novas maneiras de relacionamento do indivíduo com os outros e consigo" (2001, p. 13).

Além disso, Thompson atenta também para um conceito classificado por Castells (2009) como a extinção da geografia, em que formas de comunicação geram um grau de distanciamento do espaço temporal que varia com as circunstâncias comunicacionais e o tipo de meio técnico empregado (p. 28). Milton Santos (2007) complementa tal discussão ao afirmar que "hoje, cada momento compreende, em todos os lugares, eventos que são interdependentes, incluídos em um mesmo sistema de relações" (p. 3).

Com o evoluir da web, passamos a conviver com as redes sociais de forma constante e cotidiana. Para Raquel Recuero (2011), esse conceito de redes fundamenta-se em atores e suas conexões, ou seja, pessoas que partilham dos mesmos objetivos. Milton Santos (2015) classifica esse momento atual que se vive como um ambiente que "em lugar do cidadão formou-se um consumidor, que aceita ser chamado de usuário" (p. 25).

A cada dia, o cidadão redescobre seu papel, valendo-se das tecnologias como ferramenta de um agendamento cidadão. Isso, para Santos (2015), ocorreu de forma sistemática e rápida:

Nessa realidade, tais mudanças perversas não se deram apenas paralelamente, mas sistematicamente, o que acentua sua força ideológica, na medida em que os fenômenos correspondentes acabam por se justificar a partir de suas próprias relações causais, isto é, naturalmente (p. 25).

Ainda de acordo com o autor, atualmente "a comunicação entre as pessoas é feita por meio de coisas” (p. 30). E é aí que entram as 
redes sociais e microblogs, nesse papel mediador. Facilmente confundido com o conceito de redes sociais, encontramos a definição de microblog, que de acordo com Zago, possui as funcionalidades de blogging, unida às redes de interação.

Nesse sentido, este artigo busca refletir acerca da repercussão feita via Twitter da cobertura feita pelo Jornal Nacional nos manifestos de junho de 2013 no Brasil, para com isso perceber ou não tais conceitos de agendamento, definido por Javier Cremades (2009) como micropoder.

Motivado por entender academicamente como esse processo de agendamento cidadão se dá e como o internauta/telespectador se vale das novas ferramentas para conquistar um espaço antes exclusivamente midiático, o presente artigo objetiva analisar o papel da hashtag como possível mecanismo de voz do cidadão. Para tal, foram monitorados via plataforma Scup, os tweets de opinião disparados com a hashtag \#JornalNacional entre os dias 17 e 21 de junho de 2013.

Após a obtenção dos dados quantitativos, passou-se para a etapa qualitativa, onde os tweets foram ordenados em categorias e subcategorias com a finalidade de destrinchar sua intenção na rede. Essa segunda parte do processo foi fundamental para a criação das inferências necessárias sobre a problemática central do artigo, que é entender como o cidadão está se redescobrindo e se reinserindo nas redes sociais por meio das novas ferramentas e como isso gera (ou não) um agendamento social. O foco, no entanto, está na análise do conteúdo coletado, e em um desentranhamento sobre crítica da mídia. Isso, porquê entende-se que levar em conta apenas o momento de crítica da mídia é restringir o potencial de reversão do quadro, bem como as opiniões positivas e neutras, que serão apresentadas a seguir.

\section{Do 1.0 ao 3.0}

A web passa por alterações e adaptações desde o seu início, na década de 1960. Primeiro era informação estática. Depois, veio o período da interatividade na construção daquilo que era publicado. Porém, surge a necessidade de repensar o fluxo intenso de conteúdo, o que origina uma nova fase. Oriundo da década de 1990, a ideia de web 1.0 surge na era world wide $w^{2} b^{3}$ descrita por Castells (2003) como a

\footnotetext{
${ }^{3}$ De acordo com Tim Berners-Lee: "A World Wide Web (termo da língua inglesa que, em português, se traduz literalmente por "teia mundial"), também conhecida como Web e WWW, é um sistema de documentos em hipermídia interligados e executados na Internet".
} 
época da extinção da geografia. Em um espaço em que os internautas eram apenas consumidores, a web 1.0 apresentava uma estrutura estática diferente daquela utilizada atualmente. Nela, o internauta fazia buscas sem ter a chance de ajudar na construção do conteúdo. Essas características são descritas por McQuail (2003) como uma divulgação de informação massiva e unidirecional.

A evolução de consumo para um formato de interatividade dá origem ao momento 2.0, cuja criação de conteúdos e compartilhamentos fazem parte do ambiente web. O termo web 2.0 é creditado à Tim O'Reilly, que propôs uma mudança para uma internet que serve como plataforma em que a regra fundamental é o aproveitamento da inteligência coletiva feita por meio do compartilhamento de informações em rede $^{4}$. Um dos pilares mais fortes dessa troca de comportamento é, certamente, a participação. Shirky (2011) propõe que a cultura participativa é aquela em que as novas tecnologias permitem que seus usuários criem de forma colaborativa com o outro.

A proposta de O’Reilly é de que os sites já não são estáticos e focam no consumidor e na usabilidade dos buscadores. É o marco de popularização da internet. Por meio das mídias e redes sociais, o internauta passa a ter voz e mais. E é nesse cenário que começa a ser delineada a web 3.0, que absorve o conceito de empoderamento sugerido por Castells (2009) em que um canal é utilizado pelo sujeito discursivo no seu papel de ator social para assim interagir com outros atores e consolidar as identidades coletivas, ou seja, o internauta possui autonomia sobre o conteúdo produzido e publicado. Ainda Wolton (2003, p. 32) diz que "se uma tecnologia de comunicação desempenha um papel essencial, é porque simboliza, ou catalisa, uma ruptura radical na ordem cultural ocorrendo simultaneamente na sociedade".

A ideia de web 3.0 surge pela necessidade de conectar de forma interativa o homem e a máquina. Como resultado, informações e linguagens funcionariam de forma mais inteligente. Enquanto a web 2.0 utiliza a internet para conectar pessoas, a Web 3.0 servirá para conectar informações. É uma internet cada vez mais próxima da inteligência artificial. "A Web 3.0 é uma extensão da atual Internet na qual é dado significado à informação, permitindo que computadores e pessoas trabalhem melhor em cooperação" (BERNERS-LEE, 2002, p. 1).

\footnotetext{
${ }^{4}$ Definição encontrada no site oficial de OReilly: http://oreilly.com/pub/a/web2/archive/what-is -web-20.html?page=5 com tradução livre dos autores.
} 


\section{Redes sociais e microblog}

O mundo muda a cada instante e a velocidade dessa mudança traz dinamismo ao processo humano de registro e socialização. Para tal, cada vez mais passamos tempo conectados em redes sociais, que, de acordo com Recuero (2011), tem as raízes entrelaçadas com a internet e mediadas pelo computador. O conceito dessas redes gira em torno da ideia de que pessoas ou organizações partilham de valores e objetivos comuns. A horizontalidade e a descentralização de informação também caracterizam as redes sociais. Em obra anterior, Recuero (2009), apresenta rede social como um conjunto de dois elementos: atores - no caso pessoas e corporações - e suas conexões - que são as interações e laços sociais.

Uma rede, assim, é uma metáfora para observar os padrões de conexão de um grupo social, a partir das conexões estabelecidas entre os diversos atores. A abordagem de rede tem, assim, seu foco na estrutura social, onde não é possível isolar os atores sociais e nem suas conexões (p. 24).

Um conceito por vezes mal empregado no universo das mídias sociais é o que trata de microblog. Para Orihuela (2011), a definição seria "uma mistura entre blog, rede social e mensageiro instantâneo". Zago amplia a definição do autor com considerações a respeito da definição de microblog com base nas funcionabilidades do Twitter:

Tentando ampliar as considerações do autor, pode-se dizer que o Twitter seria blog na medida em que envolve a publicação de conteúdo em ordem cronológica inversa. Seria rede social porque nele cada pessoa é representada por um perfil, há uma lista de contatos, e pode-se interagir uns com os outros (ZAGO, artigo web ${ }^{5}$ ).

Santaella (2011) classifica que a partir do Twitter, o internauta teve sua noção de sociabilidade alterada, visto que até então os usuários levavam para o ciberespaço vínculos sociais que já existiam previamente, como amigos, colegas de trabalho, familiares.

\footnotetext{
${ }^{5}$ http://www.gabrielazago.com/2008/10/afinal_o_que_e_um_microblog/.
} 


\section{A utilização da Rede Social como oportunidade de propagação}

Brasil, junho de 2013. Seleções de futebol de países campeões desembarcavam em diversas capitais brasileiras. Os brasileiros sentiam de perto o gosto de uma das suas principais paixões: o futebol. Parecia que nada afetaria o evento. O governo poderia, inclusive, aproveitar o momento para subir as passagens em São Paulo para R \$3,206. Propagandas publicitárias incentivavam o patriotismo do futebol mandando o povo "ir para a rua, pois a rua é a maior arquibancada do Brasil" . O povo, por sua vez, obedeceu. Porém, a motivação não era o futebol.

Com um posfácio dedicado aos manifestos de junho de 2013 no Brasil, Castells (2013) em sua obra Redes de Indignação, argumenta que a ampla transformação tecnológica baseada na interatividade da internet faz emergir um novo padrão estrutural social, sendo esse o principal alicerce onde os movimentos em rede do século XXI se constituem.

Indignados pelo aumento da passagem, o movimento paulista Passe Livre foi para as ruas protestar. O brasileiro, movido por essa ideia, parou o país com manifestações diversas. Castells (2013) descreve que um movimento social tem origem na insustentabilidade de alguma condição cotidiana da maioria. Isso faz com que as pessoas nutram uma desconfiança pelas autoridades que governam e administram a sociedade.

Cremades (2009) descreve essa mudança de postura social como micropoder, que significa o poder individual do cidadão em expor de forma relevante sua opinião - até então rejeitada - graças às comunicações eletrônicas (p. 17). Ou seja, o micropoder coloca os cidadãos como os verdadeiros protagonistas das mudanças sociais uma vez que "ninguém fará como os cidadãos, tão bem como os cidadãos, se os cidadãos não a fizerem".

Esse cenário faz com que as novas tecnologias de informação e comunicação delineiem um ambiente de liberdade da palavra pela possi-

\footnotetext{
${ }^{6}$ Folha de São Paulo Manifestações não foram pelos 20 centavos - Retrospectiva dos fatos publicado em 27/12/2013: http://www1.folha.uol.com.br/poder/2013/12/1390207-manifestacoes-nao-foram-pelos-20-centavos.shtml Acesso em 22 jun. 2014; Jornal O Globo, 17/06/2013 p3.: Nova onda de protestos - disponível em acervo online: http://acervo.oglobo.globo.com/em-destaque/junho-de-2013-protestoscontra-aumento-da-passagens-se-espalham-pelo-pais-11101311 - acesso em 22 jun. 2014; Jornal Estadão: Em uma semana quatro protestos contra o aumento da tarifa em São Paulo versão online 13/06/2013: http://www.estadao.com.br/infograficos/em-uma-semana-quatro-protestos-contra-aumento-da-tarifa-em-sao-paulo,203763.htm - acesso em 22 jun. 2014

7 A Fiat lançou o mote publicitário Vem para a rua que a rua é a maior arquibancada do Brasil. Propaganda disponível no canal oficial empresa: https://www.youtube.com/watch?v=ERDj5OKH0eI acesso em 22 jun. 2014.
} 
bilidade de interação no ambiente social (p. 28). Castells (2013) atribui a essência emocional motivadora como uma das maiores engrenagens para a mudança social. Para o autor, o que desencadeia os movimentos sociais é a motivação emocional para desafiar poderes, associada a algum evento específico:

A teoria da inteligência afetiva em comunicação política argumenta que o gatilho é a raiva, e o repressor, o medo. A raiva aumenta com a percepção de uma ação injusta e com a identificação do agente por ela responsável. O medo desencadeia a ansiedade, associada à evitação do perigo (CASTELLS, 2013, p. 158).

Ainda para o autor, esse medo é superado pelo compartilhamento que gera um processo de ação comunicativa guiado pela identificação. Então a raiva assume o controle tornando-se uma motivação para assumir os riscos. Ou seja, o surgimento de uma audiência proativa parece irrefreável, uma vez que o usuário quer ser tido como testemunha da atualidade que alimenta o grande debate mantido pelos meios (CREMADES, 2009. p. 19).

\section{O Twitter como ferramenta de participação}

A proposta de análise do presente artigo consiste na mensuração do posicionamento dos telespectadores do Jornal Nacional que, em paralelo ao momento em que assistiam ao telejornal, utilizavam o microblog Twitter para expor sua opinião acerca da abordagem jornalística adotada pela Rede Globo entre os dias 17 e 21 de junho de 2013. Para tal, foram decupadas as edições do Jornal Nacional no período supracitado - momento em que as manifestações foram mais intensas. O objetivo dessa captura consiste em trazer empirismo à análise de posicionamento do telejornal mediante os manifestos que tomavam conta das ruas, e também analisar a força comunicacional que as manifestações populares adquirem em uma sociedade midiatizada quando o uso das ferramentas é bem utilizado.

Além disso, foram coletados os tuites disparados ao longo do período de exibição do JN. Foram aproximadamente 15 mil publicações no microblog de segunda a quinta no horário de $20 \mathrm{~h} 30$ às $21 \mathrm{~h} 30$ com a hashtag \#JornalNacional. Para esta pesquisa, foi estabelecido o recorte de $10 \%$ do total diário de tuites. As postagens contidas nesse recorte foram divididas em três categorias, conforme a tabela 1: 
Tabela 1: Categoria de análise

\begin{tabular}{|c|c|c|}
\hline Categoria & Definição & Exemplo \\
\hline Positivo & $\begin{array}{l}\text { Postagens que elogiavam o trabalho } \\
\text { executado pelo JN ao longo dos mani- } \\
\text { festos. Comentários positivos em rela- } \\
\text { ção à postura dos âncoras do JN. }\end{array}$ & $\begin{array}{l}\text { Patricia Poeta é muito linda, inteligente } \\
\text { HJornalNacional }\end{array}$ \\
\hline Negativo & $\begin{array}{l}\text { Crítica feita em relação ao posicio- } \\
\text { namento do JN durante o período de } \\
\text { manifestações. Críticas aos âncoras do } \\
\text { telejornal. }\end{array}$ & $\begin{array}{l}\text { Ridicula a Rede Globo falando das } \\
\text { manifestaçóes em Såo Paulo, colocando a } \\
\text { versăo made in pagoulevou! tvergonioso } \\
\text { Hijornalnacional tpasselivre }\end{array}$ \\
\hline Neutro & $\begin{array}{l}\text { Postagens sem opinião - ou seja, narra- } \\
\text { tiva dos fatos sem um posicionamento. } \\
\text { Posts que citavam o aparecimento de } \\
\text { pessoas e cidades também se encaixa- } \\
\text { ram nesse grupo. }\end{array}$ & $\begin{array}{l}\text { Só no Brasil mesmo, q os caras aproveitam } \\
\text { a manifestaçă pra vender capacete } \\
\text { máscara. \#JornalNacional } \\
\end{array}$ \\
\hline
\end{tabular}

Após a divisão quantitativa em positivo, negativo e neutro, os tuites foram analisados de forma qualitativa, ou seja, em termos de conteúdo. Dentre as três categorias principais, foram definidas subcategorias para agrupar as postagens de forma mais específica (Tabela 2).

Tabela 2: Subcategorias de análise

\begin{tabular}{|l|l|}
\hline Subcategoria & Definição \\
\hline Âncora & $\begin{array}{l}\text { Postagens relacionadas a comentários ou críticas a postura dos âncoras do } \\
\text { telejornal. }\end{array}$ \\
\hline Cobertura & $\begin{array}{l}\text { Tratam sobre a forma de abordagem que a Rede Globo está dando para as } \\
\text { manifestações. }\end{array}$ \\
\hline Invasão & $\begin{array}{l}\text { Explicita a vontade de que a Rede Globo seja invadida durante os mani- } \\
\text { festos. }\end{array}$ \\
\hline Futebol & $\begin{array}{l}\text { Publicações de repúdio ao tempo utilizado para noticiar a Copa das Con- } \\
\text { federações. }\end{array}$ \\
\hline Postura editorial & $\begin{array}{l}\text { Tratam da forma como a Rede Globo reafirma o seu compromisso com } \\
\text { a verdade. }\end{array}$ \\
\hline Opinativo & $\begin{array}{l}\text { Mostram as opiniões geradas em relação aos acontecimentos inseri- } \\
\text { dos na manifestação - como, por exemplo, uma crítica feita à depre- } \\
\text { dação de lugar público. }\end{array}$ \\
\hline Facebook & $\begin{array}{l}\text { Subcategoria criada especificamente para o dia } 3 \text { em que o Facebook } \\
\text { sai do ar durante o telejornal. }\end{array}$ \\
\hline
\end{tabular}

Tabela 2: Subcategorias de análise 


\section{Dia 1: 17/06/2013}

Na segunda-feira, 17, o Jornal Nacional iniciou às $20 \mathrm{~h} 30$ e terminou às $21 \mathrm{~h} 18$, totalizando 48 minutos no ar. Destes, 24 tratavam das manifestações, 13 da Copa das Confederações (que havia iniciado no sábado anterior) e cinco minutos destinados a notícias gerais tanto nacionais quanto internacionais não relacionadas com nenhum dos pontos já citados. O telejornal foi dividido por dois intervalos de dois minutos de duração.

Além disso, faz-se importante destacar que William Bonner não estava na bancada do jornal e sim na Arena Recife de onde falaria ao vivo sobre a Copa das Confederações. Antes do primeiro intervalo comercial, Patrícia Poeta falou sobre a política editorial do JN e reforçou o compromisso com a imparcialidade e com a verdade dos fatos.

No mesmo período de jornal - entre $20 \mathrm{~h} 30$ e $21 \mathrm{~h} 30$ - foram feitas no Twitter 2.795 menções ao Jornal Nacional, sendo analisadas 10\% dos tuites de conteúdo relevante para o presente artigo, o que totalizou 280. A partir deste total, temos a seguinte divisão conforme a tabela 3.

Tabela 3: Divisão por categoria do Dia 1

\begin{tabular}{|l|l|}
\hline Negativos & 222 \\
\hline Positivos & 12 \\
\hline Neutros & 46 \\
\hline
\end{tabular}

Das 222 postagens da categoria negativa, 11 foram subcategorizadas como âncora em que Patrícia Poeta ou William Bonner eram citados de forma direta:

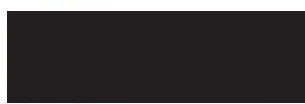

@realwbonner, seria uma boa se vc comentasse as vaias á presidente Dilma ocorrida na abertura da Copa das Confederações. \#jornalnacional

A maior incidência de postagem se agrupa na subcategoria cobertura: 


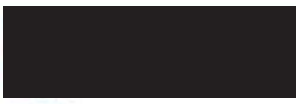

$\because$ Seguir

Vamos ouvir as mentiras do \# JornalNacional

a mesponder ta Rntweetar \# Cortir ... Mais

Trinta e quatro posts se enquadravam na subcategoria invasão visto que explicitavam a vontade de que os manifestantes invadissem o prédio da Rede Globo:

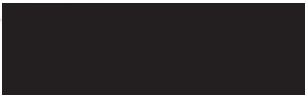

\#HACKEIAG1

-2 Seguir

Eu acho é pouco, deviam invandir a transmissão do \#JornalNacional , kkkkk

*_ ${ }^{*}$ Sonho!

Na subcategoria futebol o público fez questão de reafirmar por meio de 51 posts seu desinteresse com as notícias relacionadas à Seleção Brasileira.

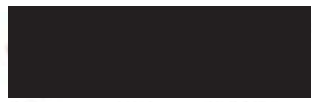

-2 Seguir

\section{Meus Deus!!! Quem quer saber de Copa das Confederaçōes. \#JornalNacional}

A postura editorial do telejornal tratou quase que unicamente sobre o pronunciamento ao vivo de Patrícia Poeta:

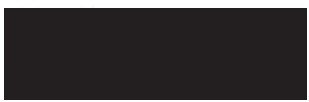

ㄴ. Seguir

\section{Alguém avisa pra Patrícia que năo săo os 20 centavos! São direitos! \#jornalnacional}

*h flesponder 23 Rentweetar * Curtir ... Mais

Entre os 12 tuites positivos, 8 abordavam a boa performance de $\mathrm{Pa}$ trícia Poeta no JN - subcategoria âncora, enquanto os demais elogiavam a matéria sobre a seleção do Taiti. Já as menções classificadas como neutras, 
englobavam as postagens feitas referentes às menções sobre alguma pessoa ou cidade que apareceu no telejornal sob o contexto dos manifestos - subcategoria cobertura.

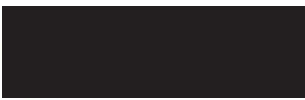

$\stackrel{-}{\text { Seguir }}$

To assistindo \#jornalnacional falando sobre

a manifestaçao em SP! \#vempraruabrasil

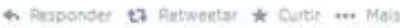

\section{Dia 2: 18/06/2013}

A edição de terça-feira, 18, do JN teve início às 20 h40 e final às 21 h35, totalizando 55 minutos de exibição. Destes, 41 foram destinados aos manifestos, 8 para a Copa das Confederações e 3 para as notícias em geral. Apenas um bloco de 3 minutos de intervalo comercial dividiu o telejornal. Também faz-se importante salientar que William Bonner está de volta à bancada do JN e o mesmo trata da importância de priorizar o que acontece no país. As pautas relacionadas à Copa das Confederações são abordadas por Galvão Bueno. Pela primeira vez, a Rede Globo usa seu perfil oficial para anunciar a cobertura dos manifestos:

\section{(1) Globoo $\simeq$ Segult \\ Veja no \#JornalNacional a cobertura \\ completa das manifestações que ocorrem \\ pelo país e as principais notícias do dia. \\ bit.ly/CP3PMM

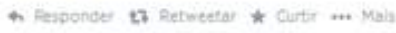

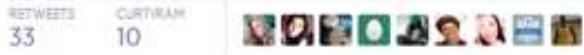 \\ $16.25-16$ de jun de 2013}

Além disso, a hashtag \#JornalNacional em análise no presente artigo entra para os Trending Topics nacionais, sendo o único veículo a alcançar o ranking dentre os mais falados em termos de cobertura. No Twitter, foram 3.037 menções no período de exibição do telejornal. Os 10\% analisados totalizaram 303 tuites, que foram divididos conforme a tabela 4 . 
Tabela 4: Divisão por categoria do Dia 2

\begin{tabular}{|l|l|}
\hline Negativos & 117 \\
\hline Positivos & 24 \\
\hline Neutros & 112 \\
\hline
\end{tabular}

Ainda que seja perceptível um percentual de quase metade de postagens negativas, é possível perceber que a mesma foi a categoria com maior queda, perdendo força para as postagens neutras. Como postagem neutra foram categorizados tuites que citavam o Jornal Nacional, porém sem uma tendência. Um exemplo disso, já utilizado no dia anterior são as postagens citando uma cidade que aparece no manifesto, que compõe 60 posts dos subcategorizados como neutros:

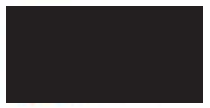

Bom se era para aparecer, Maringá conseguiu passou no \#jornalnacional \#vempraruamaringá

Além disso, a subcategoria cobertura foi fundamental no crescimento da expressão neutra. Isso significa que o público narrou literalmente o que acontecia no jornal, englobando postagens sobre o que o telejornal está falando sobre o assunto, porém sem expressão de opinião, em 32 postagens:

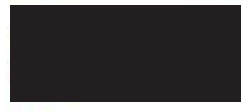

․ㅡ Seguir

\section{Manifestaçōes tomando de conta do noticiário \#jornalnacional}

Com o aumento das postagens neutras, surge uma nova subcategoria, a opinativa. Nela, vinte posts expunham a opinião sobre os manifestos, no entanto, tais posicionamentos eram relacionados a fatores que não o telejornal, como, por exemplo, abuso de autoridade da polícia, xingamentos à FIFA e ao governo e repúdio aos baderneiros. 


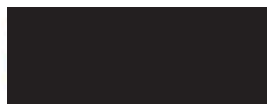

-르 Seguir

Isso q assisto no \#jornalNacional \#JN n é mais \#vandalismo é \#terrorismo mesmo estou \#apavorada e $\mathrm{c}$ medo do q mais possa vir por ai

* Ariponder ta Retweetar * Curtir.... Mas

Apenas duas subcategorias foram encontradas entre os tuites positivos: postura editorial e cobertura. A subcategoria postura editorial sinaliza uma aprovação à mudança de postura da Rede Globo perante os fatos, percebida em 16 postagens. Já a subcategoria cobertura mostra em 8 posts uma aceitação sobre a cobertura dos manifestos em si, elogiando imagens e tempo de duração.

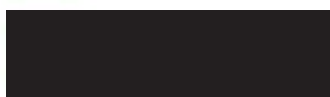

- 2 Seguir

\section{Parabéns \# JornalNacional pela cobertura das manifestaçŏes! Imparcial, como manda o princípio ético do jornalismo.}

+ Respanoer ta Recovettar * Curtir .... Mais

Em comparação com o dia anterior, a categoria negativa apresentou aumento nas seguintes subcategorias:

- Tuites relacionados aos âncoras: além da volta de William Bonner ter sido repercutida, Patrícia Poeta foi citada em $85 \%$ das vezes por estar de cara fechada durante a apresentação do telejornal.

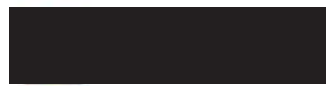

-2 Seguir

\section{Patricia Poeta Parece que ta de LUTO PQ? Salve o Povo Brasileiro Que Ta Acordando E Ela Triste? Si Manca sò pq ganha MILHOES \#jornalnacional}

- Em relação à cobertura as principais postagens, chamam de "papelão" a decisão da emissora em tirar as canoplas ${ }^{8}$ dos microfones durante a cobertura dos manifestos na rua. Também foram postadas reclamações sobre o esquecimento de algumas cidades.

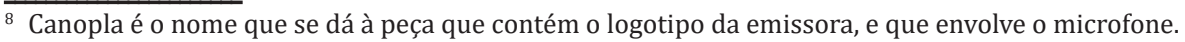




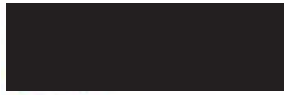

\section{Reporter do \#JornalNacional com MICROFONE sem o \#globo}

\section{Curitios, Faranis}

\& Responder va Retweetar * Cartir w Mas

- A subcategoria postura editorial caracterizou o maior aumento. De forma quase unânime, as postagens se referiam em tom crítico à mudança súbita de postura da Rede Globo sobre os manifestos em relação ao dia anterior. As hashtags \#globomente e \#foraglobo tiveram grande expressividade. Também em comparação ao dia anterior, houve queda de tuites relacionados na categoria que mencionava a invasão à Rede Globo e as postagens de repúdio ao tempo gasto com a cobertura da Copa das Confederações - subcategoria futebol.

\section{Dia $3-19 / 06 / 2013$}

A edição de quarta-feira, 19 , iniciou às $20 \mathrm{~h} 30$ e teve fim às $21 \mathrm{~h} 26$, totalizando 56 minutos no ar. Do tempo total, 45 minutos foram destinados às manifestações em várias capitais e cidades brasileiras. Cinco minutos foi o tempo dado para tratar de Copa das Confederações e aqui é importante levar em consideração que nesse dia, Brasil e México jogaram no turno da tarde em uma partida que valia a classificação para a próxima fase da competição. Três minutos foram destinados para abordagem de notícias de cunho geral. Houve apenas um intervalo comercial com duração de 3 minutos. No Twitter, foram 3.373 menções referentes ao JN, disparados durante a exibição do telejornal. Deste total, interessam para esta pesquisa $10 \%$, ou o equivalente a 333. A divisão nas categorias está na Tabela 5.

Tabela 5: Divisão por categoria do Dia 3

\begin{tabular}{|l|l|}
\hline Negativos & 67 \\
\hline Positivos & 40 \\
\hline Neutros & 226 \\
\hline
\end{tabular}

Em comparação ao dia anterior, as categorias neutras e positivas obtiveram um aumento, sendo que as postagens agrupadas como negativas obtiveram uma queda maior do que a sua metade anteriormente. 
No quesito neutro houve a necessidade da criação de uma nova subcategoria dedicada especificamente ao dia: Facebook. Isso se deu devido ao fato da rede social ter sofrido um bug ao longo da transmissão do telejornal. Em 89 das publicações, foram tuitados posts do tipo:

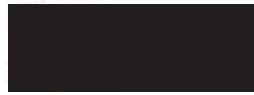

$$
\text { \$2 } 2 \text { Follow }
$$

Pessoas que estavam investindo em futuras fodinhas estão revoltadas com a paralisação do Facebook, agora no Jornal Nacional

G Vew tramsiation

\& Rebly ea Rotweet \& Fworta ... More

Além disso, a categoria neutra apresentou outras três subcategorias: postagens referentes a pessoas ou lugares que apareceram na cobertura das manifestações - 56 tuites, e comentários sobre a cobertura efetivamente, ou seja, os fatos que estavam sendo narrados como, por exemplo:

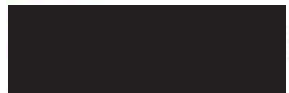

$$
\text { -2 Seguir }
$$

Estava vendo agora no \#JornalNacional da @rede_globo que as manifestaçőes andam sendo mais pacíficas, sem haver violência! \#Legal

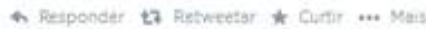

Além disso, a subclassificação postura editorial em sua maioria tratava do aumento de tempo do JN:

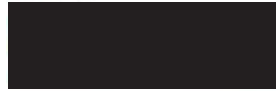

+느 Seguir

\section{Gente, kd \#AmoraVida? \#JornalNacional estendido hoje???}

a Perponder. 27 Retweetar \& Curtis .... Mas

Em relação às postagens positivas, $90 \%$ das publicações eram de cunho editorial em que a mudança de postura do telejornal era elogiada em tuites como, por exemplo: 


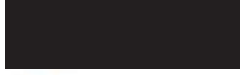

Na MINHA opinião, hoje o \#JornalNacional fez uma cobertura das manifestacŏes nota $10 !$

\& Reiponcer 27 Retweetar $\star$ Curtir .... Mas

Negativamente, as postagens seguiam o cunho de crítica à postura editorial do telejornal e à forma em que os fatos eram apresentados.

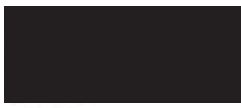

느 Seguir

\section{A imagem e citacão sobre o carro da Record em chamas foi até anunciado no \# JornalNacional da \#Globo. Suspeito năo?}

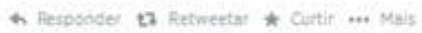

\section{Dia 4: 20/06/2013}

$\mathrm{Na}$ quinta-feira, 20, a Globo não exibiu a novela das $18 \mathrm{~h}$ e o JN teve início às $18 \mathrm{~h} 30$ em uma edição especial que durou até as $21 \mathrm{~h} 22$. Nessa ocasião, em 4 minutos foi dado o resumo da Copa das Confederações, em 2 minutos, a previsão do tempo e, fora isso, o único assunto abordado foram as manifestações. No período de tempo de $2 \mathrm{~h} 52$, foram publicados 5.078 tuites, dos quais foram analisados no presente artigo 507, ou 10\% do total. A tabela 6 apresenta a divisão nas categorias positivo, negativo e neutro.

Tabela 6: Divisão por categoria do Dia 4

\begin{tabular}{|l|l|}
\hline Negativos & 233 \\
\hline Positivos & 81 \\
\hline Neutros & 193 \\
\hline
\end{tabular}

Após uma quarta-feira desparelha, novamente há uma aproximação entre os números das postagens neutras e negativas. No entanto, diferentemente de todos os outros dias, a maioria dos posts negativos não foi sobre manipulação de informação, e, sim, reclamação sobre o tempo que o telejornal ficou no ar e a quantidade de programação que foi retirada em função disso (Malhação e novelas das 18h e 19h). 
Além disso, nesse discurso apresenta-se a crítica que após uma hora e meia de transmissão, tanto imagens quanto conteúdo transmitido tornaram-se repetitivos e desinteressantes.

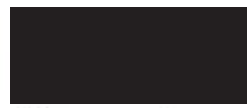

a 2 Follow

Nunca vi uma edição tão longa do Jornal

Nacional

6 vew vansiation

4h Pepry ta Betweet $\star$ Favonte ... More

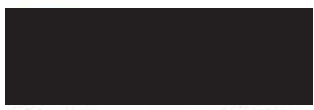

2. 2 Follow

Se tivessem feito uma ligação direta do xvideos no lugar desse jornal nacional, teria sido mais proveitoso

Q view trinsation
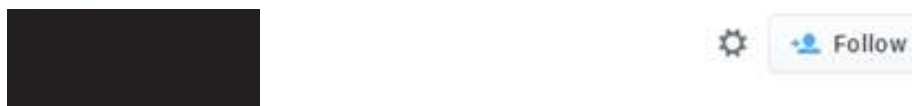

\section{Eita, teve 3 h de jornal nacional \\ 6 Viaw transiation \\ 4 Reply $\mathbf{2}$ Retweet $\star$ Farorite ... More}

Também foi motivo de crítica o esquecimento por algumas cidades, como, por exemplo:

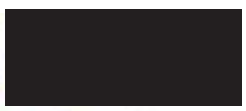

at $=$ Follow

+ de 3 horas no ar e Jornal Nacional não

falou de João Pessoa, gratos.

Q view transition

4 Regly ea hotweet * Fivonte ... More

A zona neutra, como já apresentado antes, centrou-se fundamentalmente em narrar passo a passo o que passava na tevê, enquanto as postagens positivas, da mesma forma que na noite anterior, elogiavam a troca de postura da Rede Globo e do JN para com as manifestações. 


\section{Conclusões gerais}

É possível, a partir da análise dos quatro dias de cobertura do JN sobre as manifestações de junho de 2013 no Brasil e sua repercussão no Twitter, perceber algumas tendências e posturas que não generalizam necessariamente o posicionamento do usuário do microblog, mas que apontam para alguns possíveis cenários:

O posicionamento de defesa em forma de discursos formais feitos pelos âncoras do telejornal conversam com o que está sendo publicado a respeito na rede. Termos como "primamos pela verdade" - utilizado por Patrícia Poeta, e "entendemos que esse é o assunto de maior importância na atualidade" - utilizado por William Bonner, caracterizam respostas às postagens que fazem essa crítica sobre o posicionamento e tempo dado para os manifestos ao longo do telejornal.

Um dos assuntos mais citados no microblog no primeiro dia é o fato de William Bonner estar falando de futebol enquanto as ruas estão lotadas de cidadãos em protesto. No dia seguinte a essa insatisfação postada em massa na web, o âncora já está de volta à bancada - a ideia inicial do telejornal é que Bonner acompanharia a seleção pelos estádios da Copa ao longo de toda aquela semana. Também no segundo dia, a Rede Globo passa a utilizar o Twitter para se comunicar por meio de postagens do tipo "não perca hoje no \#JornalNacional a cobertura completa sobre as manifestações". Ainda que seja a menor das métricas, as menções positivas foram as únicas que tiveram um crescimento constante, acompanhando o tempo de transmissão dado.

$\mathrm{O}$ aumento brusco de postagens neutras pode ser um indício de que o cidadão quer um espaço para participar. Isso pode ser percebido no fato que a subcategoria neutra mais utilizada reunia justamente postagens compostas por elementos autopromoção, do estilo mãe, estou na Globo. Embora os quesitos de análise considerem o tempo reservado para a cobertura das manifestações, a categoria negativa mais citada não tratava sobre o tempo dividido com o futebol, mas, sim, a postura editorial na hora de reportar os fatos. Igualmente a postura editorial é a mais elogiada, tomando força a partir do segundo dia, quando se percebe que há um movimento de correspondência entre a organização do telejornal e o que o telespectador está manifestando na web. Essa "curva" proporcional aos tweets da web servem para fundamentar a força adquirida pelo internauta nos últimos anos, o que deu início a um processo de agendamento social. 
Também é possível perceber por meio da análise do discurso crítico, proposto por Norman Fairclough em Language and Power (1989) e Critical Discourse Analysis (1995), que os tweets que se valem da hashtag utilizada servem para ilustrar mudanças no processo de recepção do telespectador que se torna, também, o internauta. Essa nova ambiência e nova forma de recepção e capacidade de crítica social por parte dos atores sociais é facilmente percebida pela teoria de circulação, recepção e produção de sentido proposta por Eliseo Verón (1997), visto que o conteúdo sai da televisão, passa pelas redes sociais - que representam um novo sentido e focam em um primeiro momento na indignação - e retorna para a TV através de um novo posicionamento melhor adequado ao desejo de seu público.

\section{Considerações finais}

Com os dados utilizados na construção desse estudo é possível perceber um olhar mais atento dos meios de comunicação tradicionais para os novos canais de propagação de ideias e opiniões. A análise apresentada no presente artigo é mais um estudo entre os que vêm surgindo ao longo dos anos e que trazem empirismo a esse novo cenário em que a web é ferramenta de propagação em um ambiente full time como proposto por Wolton. $\mathrm{O}$ artigo também destaca - ainda que não de forma generalista - como o cidadão tem conseguido se apropriar desse novo cenário, tornando reais conceitos científicos sobre a comunicação na web e, mais do que isso: a web como forma de crítica da mídia - como é o caso do empoderamento proposto por Castells, que "embora não seja um conceito novo, está explicitado nas reações vistas nas ruas e no uso de microblogging".

$\mathrm{O}$ artigo encontra indícios de que o cidadão está redescobrindo seu papel, utilizando as ferramentas a seu alcance para criar um agendamento que ilustra o conceito de micropoder proposto por Javier Cremades. Além disso, consciente de que os processos de comunicação web passam por constantes mudanças, tanto teórico-filosóficas como tecnológicas, tal estudo se propõe a incitar pesquisas posteriores que possam enriquecer o ramo em termos de crítica da mídia e construção de agendamento web. 


\section{REFERÊNCIAS}

BERNERS-LEE, Tim, Information Management: A Proposal. Disponível em: http:// www.w3.org/History/1989/proposal.html - acesso em mai/2014

BORELLI, Silvia. PRIOLLI, Gabriela. A deusa ferida: por que a Rede Globo não é mais a campeã absoluta de audiência. São Paulo: Summus, 2000.

CAPARELLI, Sérgio. Estudo sobre a televisão brasileira (tese de doutorado). França: Universite de Paris II. 1980.

CASTELLS, Manuel. A galáxia da internet: reflexões sobre a internet, os negócios e a sociedade. Rio de Janeiro: J. Zahar, 2003.

Redes de indignação e esperança: movimentos sociais na era da internet. São Paulo: Zahar, 2013.

CREMADES, Javier. Micropoder - a força do cidadão na Era Digital. São Paulo: SENAC São Paulo, 2008.

FAIRCLOUGH, Norman, Language and power, Inglaterra: 1989 Longman Group UK Limited

Group UK Limited , Critical Discourse Analysis, Inglaterra: 1995 Longman

LÉVY, Pierre. A inteligência coletiva: por uma antropologia do ciberespaço. 8. ed. São Paulo: Loyola, 2011.

MATTOS, Sérgio. A televisão no Brasil: 50 anos de história (1950-2000). Salvador: PAS: Ianamá, 2000.

MCQUAIL, Denis. Teoria da comunicação de massa. Lisboa: Fundação Calouste Gulbenkian, 2003.

PATERNOSTRO, Vera Íris. O texto na tv: manual de telejornalismo. Rio de Janeiro: Campus, 1999.

RECUERO, Raquel. Redes sociais na internet. Porto Alegre: Sulina, 2009.

. Conversação em Rede - A comunicação mediada pelo computador e redes sociais na Internet 2 ed. Porto Alegre: Sulina, 2011. 
SANTAELLA, Lucia. LEMOS, Renata. Redes Sociais Digitais - a Cognição Conectiva do Twitter. São Paulo: Paulus, 2010.

SANTOS, Adriana. Cartões-postais: lugares de memória - Análise de duas campanhas promovidas pela TV Globo Minas para eleger as imagens que mais representam Belo Horizonte e Minas Gerais publicado em Revista Espcom número 2, UFMG. Disponível em: http://www.fafich.ufmg.br/ espcom/revista/numero2/artigos.html - Acesso em mai/2014

SANTOS, Milton. Espaço do Cidadão: O Vol. 8. Edusp, 2007.

A revolução tecnológica e o território: realidades e perspectivas.

Terra Livre, n.9, 2015.

SHIRKY, Clay. A cultura da participação: criatividade e generosidade no mundo conectado. Rio de Janeiro: Zahar, 2011

THOMPSON, John B. A mídia e a modernidade: uma teoria social da mídia. 3. ed. Petrópolis: Vozes, 2001.

VERÓN, Eliseo. Esquema para el análisis de la mediatización. Diálogos n 48. Buenos Aires, 1997. p. 9-16

WOLTON, Dominique. Internet, e depois? Uma teoria crítica das novas mídias. Porto Alegre: Sulina, 2012. 